\title{
PASSENGER INFORMATION SYSTEMS IN PUBLIC TRANSPORT
}

The article deals with establishment of passenger information systems which are comprehensive and not limited to one or more individual operators or transport modes. The systems should be multi-lingual, disabled adapted, both inside and outside interchanges, and combine static (i.e. timetable) and dynamic data on both public and private transport services.

\section{Introduction}

Passenger information systems in transit applications refer to the use of technology to provide travel information to passengers in order to assist their trip-making or route choice decisions either prior to departure or en route. The information provided may vary from static route, schedule and fare information to real-time vehicle location and/or estimated arrival time. Real-time information can be offered to passengers when the passenger information system is used in conjunction with GPS systems. Furthermore, passenger information might be disseminated through the use of transit operations software such as itinerary planning systems.

Passenger information is generally expected to improve the quality of transit service by improving the passenger experience. Passenger information may grant passengers a better sense of control over their trip-making decisions and/or enable them to take action to minimize their waiting times at stops, plan their transfer connections and thus reduce their overall travel time.

\section{Categories of information systems in public transport}

Information systems may be provided in three categories (Fig. 1):

- Pre-trip passenger information systems

- In-terminal/wayside information systems

- In-vehicle information systems

Various factors affect passenger trip-making decisions, including service characteristics such as frequency and coverage. Different types of information (e.g. static or real-time) and different methods for accessing that information (e.g. via the internet at home or in vehicle announcements) will likely have different effects on how passengers use different types of service (e.g. high frequency and low frequency). There is a wide variety of passenger informa-

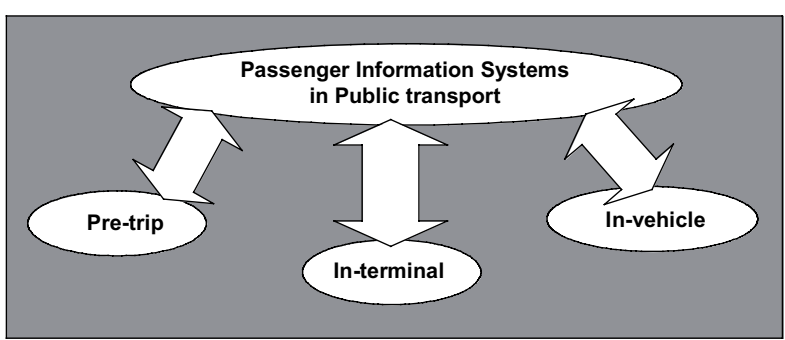

Fig. 1 Categories of passenger information systems

tion systems that are designed to influence specific passenger behaviors and decisions. Below, each of the categories of passenger information systems listed above is discussed.

\section{Pre-Trip Passenger Information Systems}

Pre-trip passenger information systems imparts to the user information relevant to the choices that are made prior to departure. These pre-trip decisions include choice of mode, route and departure time, thus enabling passengers to choose a course of action that best serves their trip purpose.

There are two types of pre-trip passenger information:

- General Service Information,

- Itinerary Planning.

General Service Information systems offer static information, such as route, schedule and fare information. This information can be accessed by phone or by consulting maps and timetables that are posted on vehicles, at stops, or on the Internet.

Itinerary planning systems allow passengers to consider a variety of factors such as travel time, walking distance, cost, and number

\footnotetext{
* Ivana Olivkova

Institut of Transport, Faculty of Civil Engineering, Technical University of Ostrava, Ostrava - Poruba, Czech Republic,

E-mail: ivana.olivkova@vsb.cz
} 
of transfers. With these criteria in mind, the passenger may choose from the alternative trip plans that connect their origin to their destination.

Passenger response to pre-trip information has been hypothesized and modeled in the literature. It is important to distinguish between low frequency, regular services (e.g. suburban and off-peak urban routes) and high frequency, irregular services (e.g. urban routes) when considering transit passenger route choice. It is generally assumed that, for low frequency services, passengers choose both the stop and the trip (i.e. scheduled departure time) before the trip begins. With high frequency services, passengers are assumed to choose only the stop prior to starting the trip.

The choice of various stops on routes that serve the passenger's destination can be modeled according to random utility theory, where each candidate stop in the choice set has some utility value that is a function of the stop's attributes. Therefore, various types of pre-trip information (e.g. schedules, estimated arrival times) might contribute to the perceived utility of a stop and have a significant impact on passenger pre-trip stop choice. For high frequency services, it is assumed that passengers develop, prior to departure, a choice set of candidate routes that serve the origin stop. Choice of the actual trip from the set of alternative routes is assumed to take place en-route. However, pre-trip static and/or real-time information can play an important role in the passenger's consideration of possible routes.

\section{In-Terminal Information Systems}

Passenger information systems that provide information to passengers while they wait at stops are designed to provide waiting customers with current information regarding delays, estimated arrival times and other real-time vehicle performance data.

The dynamic stop information system (DIS) makes it possible to inform visually and acoustically the passengers in the public transportation about the actual situation on the particular stop (Fig. 2). The system compares the time table with the actual traffic situation monitored by the following of the vehicles position with

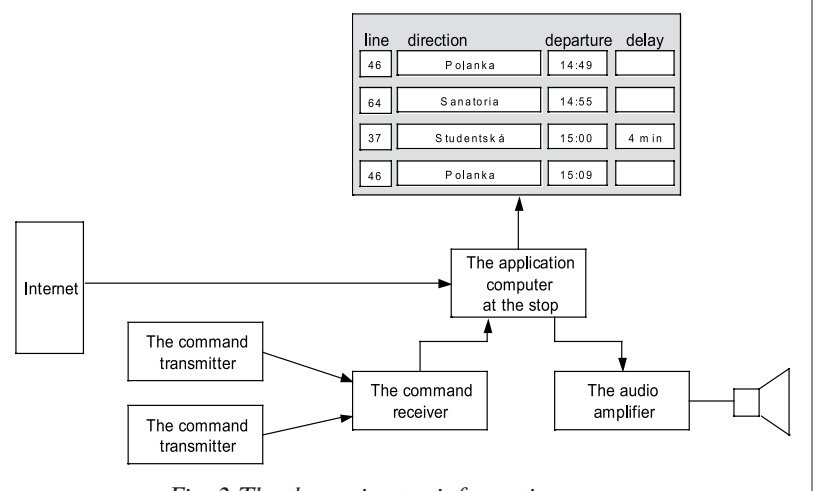

Fig. 2 The dynamic stop information system the help of the satellite navigation system GPS. The data about the bus location are transmitted from the vehicles by means of the radio communication adapter with the GSM /GPRS modulus into the central traffic information centre (CETIS). In the CETIS the data are processed and they can be completed by the time table. The information about time deviations of the buses from the time table is conveyed in the real-time with the help of the Internet (Intranet) to the application computer at the stop or at the station. The passengers are in a position to watch the information about the actual traffic situation on the large area colour display panel. The visually impaired and handicapped persons outfitted by the command transmitter can solicit the information in the acoustic form [4].

The information provided at transit stops may or may not influence passenger route choice. For low frequency, regular services, it is assumed that passengers have already chosen a stop and a trip prior to departure. Therefore, in the case of low frequency services, in-terminal/wayside information may be used to ease customer frustration and impatience during delays. However, in-terminal/wayside information can influence the passenger's en-route decision-making behavior in the case of high frequency services. For example, if more than one route serves the origin stop, the passenger may choose from among a set of approaching vehicles that serve the destination.

According to random utility theory, each approaching candidate trip has some utility associated with it, which might be a function of passenger information [3]. The utility of an approaching trip in the choice set as a function of:

- Waiting time (the difference between the estimated arrival time of a trip and the estimated arrival time of the base trip), provided by the information system

- In-vehicle travel time

- Transfer time to the connecting trip

- Number of passengers

- On-board comfort (i.e. level of crowding on-board between the origin and destination stops)

- Time already spent at the stop

\section{In-Vehicle Information Systems}

In-vehicle information systems use public address systems, either automated or performed by the operator, variable message signs and other on-board systems to communicate information to the passengers. In-vehicle information might include the name of the next stop, transfer opportunities at the stop, points of interest near the stop, and other information relating to upcoming stops. There is less opportunity to influence a passenger's route choice decision-making on a transit vehicle, since the passenger has already chosen a stop at which to board, the vehicle (or trip) and, presumably, a destination. However, some real-time information, such as the whereabouts of connecting vehicles at downstream stops might be conveyed using in-vehicle information systems. The user, then, may update the destination stop choice or begin planning the next leg of the trip based on the prevailing connection prospects. 
Like the other information systems, the provision of real-time information regarding connecting routes depends on the GPS system in place [2].

Components of in-vehicle information systems [4] - Fig. 3:

- on-board computer and control unit

- exterior signs

- interior information signs

- digital acoustic annunciator

On-board computer and control unit with back lighted keyboard and data record on memory card are determined for controlling of all peripheries in public transport vehicles as part of control and passenger information system in the required configuration: exterior and interior signs, digital acoustic unit, ticketing system, switches and traffic lights setup and GPS location. The construction solution and software enable its using both for manual operation mode and mode with automatical next stop switching, autonomous vehicle location by means of GPS and time table scanning [2].

Exterior and interior information signs indicated line number, destination, real time, tariff zone, duty announcement and other information. Digital acoustic annunciator provides acoustic infor-

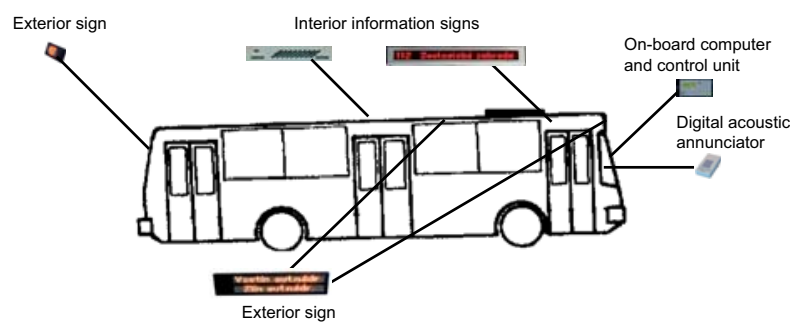

Fig. 3 Components of in-vehicle information systems mation paralelly up to three independent channels for passengers inside the vehicle, outside the vehicle and driver.

In-vehicle traveler information systems, however, may influence the behavior of passengers aboard the bus. For example, the announcement of a stop may prompt passengers expecting to alight at the stop, especially those not familiar with the system, to begin the approach to the exit doors. If this is the case, the time required to discharge all passengers at the stop may be reduced with the provision of in-vehicle information. Reduced alighting time may lead to a reduction in total dwell time at the stop, and thus affect the progression of the vehicle from stop to stop along its route.

Real-time Information makes use of GPS data to provide current vehicle performance information to users. Performance data might be used to provide either the current locations of transit vehicles or the estimated arrival times of vehicles at stops along the route. The fourth type of pre-trip information is Multimodal Traveler Information, which provides real-time and/or static traffic and transit information. Multimodal information requires transport telematics technologies that measure and estimate the current state of the traffic network as well as transit-specific technologies that provide transit information.

\section{Conclusions}

With increasing demands on the transport network, systems providing accurate, reliable and timely dynamic information to passengers are becoming increasingly important. Many public authorities wish to promote the use of public transport as a viable alternative to the private car. To travel door to door using public transport means passengers must, on occasion, use several modes. This increases potential uncertainty about the journey and interchanges. Real time information can reduce this uncertainty and can promote public transport.

\section{References:}

[1] PRIBYL, P.: Inteligent Transport Systems and Transport Telematics II., Vydavatelstvi CVUT Praha, 2007.

[2] OLIVKOVA, I.: Information Systems in Public Transport, VSB-TU Ostrava, 2004.

[3] KRIVDA, V., OLIVKOVA, I., FRIC, J.: Transport Telematics - part I., VSB-TU Ostrava, 2004.

[4] NUZZOLO, A., RUSSO, F., CRISSALI, U.: Dynamic Schedule-Based Assignment Models for Public Transport Networks, Submitted to Springer-Verlag, 2005.

[5] http://www.apex.cz. 